\title{
Experimental study of diurnal and seasonal variations in the atmospheric electric field
}

Article

Accepted Version

Shatalina, M. V., Mareev, E. A., Klimenko, V. V., Kuterin, F. A. and Nicoll, K. A. (2019) Experimental study of diurnal and seasonal variations in the atmospheric electric field. Radiophysics and Quantum Electronics, 62 (3). pp. 183-191. ISSN 1573-9120 doi: https://doi.org/10.1007/s11141-01909966-x Available at https://centaur.reading.ac.uk/86446/

It is advisable to refer to the publisher's version if you intend to cite from the work. See Guidance on citing.

Published version at: https://doi.org/10.1007/s11141-019-09966-x

To link to this article DOI: http://dx.doi.org/10.1007/s11141-019-09966-x

Publisher: Springer

All outputs in CentAUR are protected by Intellectual Property Rights law, including copyright law. Copyright and IPR is retained by the creators or other copyright holders. Terms and conditions for use of this material are defined in the End User Agreement.

www.reading.ac.uk/centaur 
Central Archive at the University of Reading

Reading's research outputs online 


\title{
EXPERIMENTAL STUDY OF DIURNAL AND SEASONAL VARIATIONS IN THE ATMOSPHERIC ELECTRIC FIELD
}

\author{
M.V. Shatalina ${ }^{1 *}$, E.A. Mareev ${ }^{1}, 1$ V. V. Klimenko ${ }^{1}$, \\ F.A. Kuterin ${ }^{1}$, and K.A. Nicoll ${ }^{2,3}$ \\ ${ }^{1}$ Institute of Applied Physics of the Russian Academy of Sciences, Nizhny Novgorod, Russia; \\ ${ }^{2}$ Department of Meteorology, University of Reading, Reading; \\ ${ }^{3}$ University of Bath, Department of Electronic and Electrical Engineering, Bath, UK.
}

In order to separate global and local effects of atmospheric electricity, measurements of the fair weather electric field were performed in Nizhny Novgorod in 2013-2018. As a result of processing 139 diurnal records from four observation points spaced 6-8 $\mathrm{km}$ apart, diurnal variations in the fair-weather atmospheric electric field for different seasons and weekdays (working days and weekends) were studied. The curve of the local diurnal variation is shown to always have two maxima. The evening maximum of the diurnal variation (19:00-20:00 UT) coincides in time with the maximum of the Carnegie curve, which is a characteristic of the global electrical circuit. The highest values of the field amplitude are reached in the winter period. The field-intensity maximum in the first half of the day (09:00-11:00 LT) is characteristic of the urban environment and shows that local effects associated with the presence of aerosol particles in the air significantly contribute to the formation of diurnal variation, especially in summer. According to the 2013-2018 measurements, the seasonal variation in the monthly-average values of the atmospheric electric field is revealed and analyzed compared with the results of measurements of seasonal variation in other regions of the globe. The obtained results allow one to reveal the role of local effects in the formation of diurnal variation in the mid-latitude areas with temperate continental climate and provide a basis for developing a theory which can explain the physical mechanisms of local effects and suggest appropriate parametrization for finding the surface electric field in the weather and climate models. 


\section{INTRODUCTION}

Diurnal variation in the intensity of the atmospheric electric field (diurnal electric-field variation in what follows) is considered to be one of the most fundamental phenomena of atmospheric electricity. For the first time, it was described almost a hundred years ago [1-3] and implies that in the absence of significant local perturbations, both meteorological (rain, thunderstorm, strong wind) and anthropogenic (due to local sources of radiation and aerosol particles), electric-field variations near the ground surface follow variations in the parameter, which is unique for the entire Earth, the so-called ionospheric potential. These variations are primarily related to the longitude distribution of electric generators, such as thunderstorm and other clouds with a developed electric structure, on the Earth. Therefore, these variations are global in nature and occur simultaneously over the entire planet, i.e., the diurnal variation of electric-field intensity, which is measured at a certain point, is a function of Universal Time (UT) of the day. For this reason, it is called unitary variation in the fair-weather field (the fair-weather criteria are discussed below in terms of the atmospheric electric measurements). The ionospheric-potential measurements are rather complicated and have been fragmentary until now [4]. Since performing the electric-field measurements near the ground surface is simpler, multiple experiments have been carried out in different locations for the past hundred years and a significant amount of the data has been accumulated [5-9]. The diurnal variation of atmospheric electric field, which has initially been detected above the ocean (see detailed references in [10]), has also been observed at the continental stations under both urban and rural conditions [11-15]. It was shown that the presence of one (in the evening hours of Universal Time) or two (in the evening hours of Universal Time and at local noon) maxima are characteristic of the above variation [16]. The detection of the diurnal variation according to data of the ground-based monitoring of the electric field requires analysis of long-term time series with allowance for the fair-weather conditions [17-19].

Recent years have shown an increasing interest in the studies of the global and local effects of atmospheric electricity because of the climate-change problems and possible influence of the anthropogenic factors and the space weather on the climatic system of the Earth. Thus, the first steps in developing an effective global network for the atmospheric-electricity monitoring, which should supply the measurement results in almost real time, have been undertaken within the framework of the 
International Project named "Global Coordination of Atmospheric Electricity Measurements" (GLoCAEM) [20]. The data from all sites are available in the identically formatted files with one-second and one-minute time resolutions along with the meteorological information (where possible) for simplicity of the electric-measurement interpretation. Analysis of the 2016 diurnal variation in electric field shows that two diurnal maxima, which are characteristic of the local influence on the potential gradient such as the "sunrise effect," are observed at the majority of the GloCAEM locations [20].

In this case, observations not only in the regions, which are the most favorable from the viewpoint of isolating the global component (the regions located far from anthropogenic contamination and above the exchange layer), but also at usual above-ground observatories in mid-latitudes including urbanized areas (see, e.g., $[20,21])$ are of great interest. Such measurements help one to clarify various factors, which influence the atmospheric electric field, and the mechanisms of such influence.

Determination of the fair-weather conditions can somewhat differ in the works by various authors. For example, absence of precipitation including mist and haze, the wind velocity exceeding $4 \mathrm{~m} / \mathrm{s}$, and the cloud amount not exceeding five oktas are considered to be the fair-weather conditions during the atmospheric electric observations in the works written by Anisimov and coauthors (see, e.g., [22]). The latest work [19] aimed at solving this problem offers the following three main criteria of fair weather: absence of hydrometeors, aerosols, and haze, so that the direct visibility range is at least $2 \mathrm{~km}$, slight amount of cumuliform clouds and the absence of stratus clouds with bottom boundary below $1500 \mathrm{~m}$, and wind velocity near the ground surface varying in the range from 1 to $8 \mathrm{~m} / \mathrm{s}$.

Even the early studies in various geographic regions show that the type of the diurnal variation of electric field substantially depends on season, i.e., seasonal variation takes place. The early works (see [5] and the discussion of the problem and comprehensive references in [23]) are indicative of the winter-time field increase in the Northern hemisphere, which was observed at numerous ground-based stations and compared with the measurement results obtained during the "Carnegie" and "Maud" sea expeditions. However, allowance for the local effects during the ground-based measurements, as well as analysis of the data from the "Mauna Loa" station located on the island of Hawaii (at an altitude of about $3400 \mathrm{~m}$ 
above sea level, i.e., above the atmospheric exchange layer) and reanalysis of the data from the "Carnegie" and "Maud" sea expeditions show that the global annual variation should have its maximum in July, i.e., during the summer period in the Northern hemisphere [23]. In this case, the issue of the presence and significance of the semiannual seasonal variation has not yet been completely clarified.

It should be emphasized that the studies of diurnal and seasonal electric-field variations are required to ensure adequate allowance for the mechanisms of functioning of the global electric circuit in modern weather-climatic models. Parametrization of the ionospheric potential, which is proposed in [24], was used for calculating diurnal and seasonal variations in the ionospheric potential using the INMCM4.0 climatic model developed at the Institute of Numerical Mathematics of the Russian Academy of Sciences. The calculation results are in fair agreement with the available experimental data and, in particular, confirm that seasonal variation has its maximum in summer months in the Northern Hemisphere when convection above land areas is more pronounced.

This work is aimed at the experimental study of diurnal and seasonal variations in the atmospheric electric field in the mid-latitude regions with temperate continental climate. The data from continuous electric-field measurements conducted for five years in the period from 2013 to 2018 at four points spaced 6 to $8 \mathrm{~km}$ were used.

\section{EXPERIMENTAL AND DATA-PROCESSING METHODS}

Figure 1 shows a layout of the points of the electromagnetic-field reception and recording on the city territory. The electric-field sensors, i.e., electrostatic fluxmeters, were located at four points in Nizhny Novgorod City, namely, on the roof of the Institute of Applied Physics of the Russian Academy of Sciences (IAP RAS), on the roof of the Institute of Physics of Microstructures of the Russian Academy of Sciences (IPM RAS), N. I. Lobachevsky State University of Nizhny Novgorod (SUNN), and on the territory of the aerology station "Nizhny Novgorod" (AS NN). Observation points in Nizhny Novgorod were spaced 6 to $8 \mathrm{~km}$ apart. 


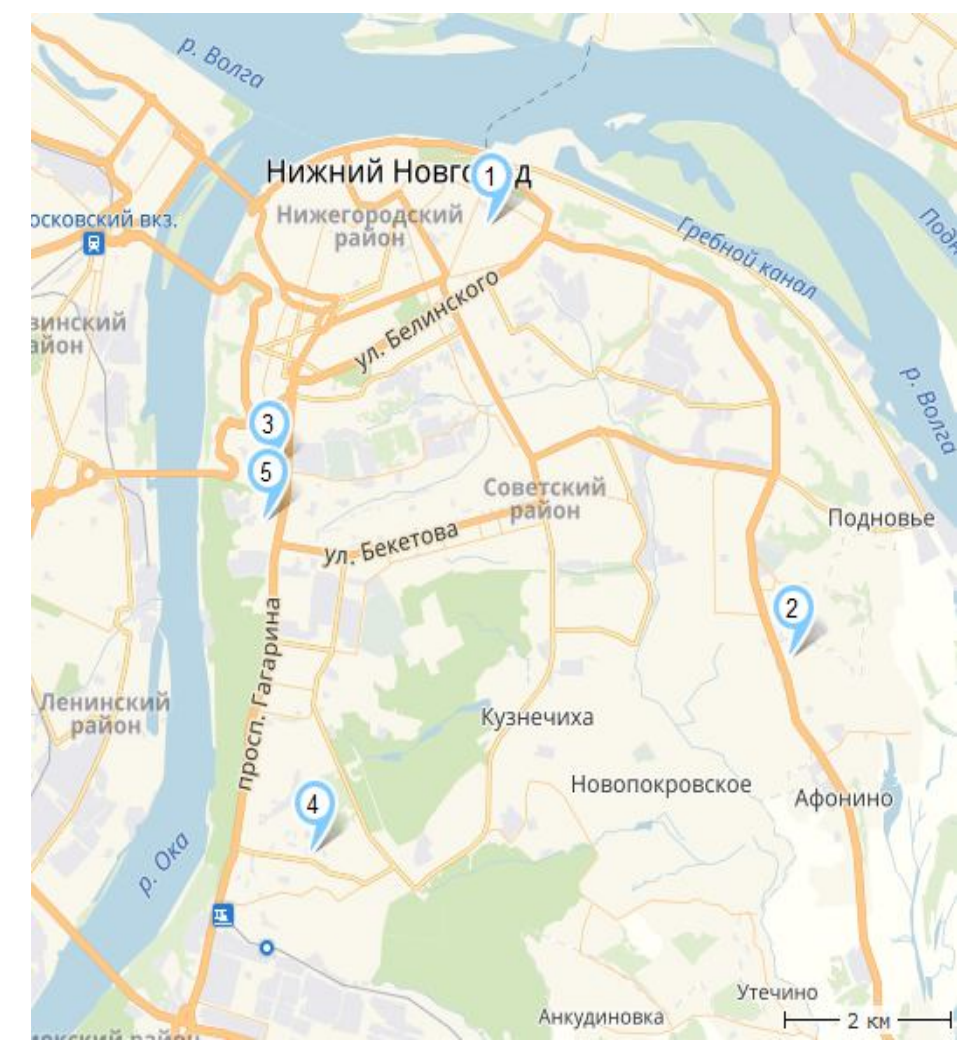

Figure 1. Layout of the measurement points in Nizhny Novgorod: fluxmeters installed on the roofs of the IAP RAS (1), IPM RAS (2), and SUNN (3), as well as on the territory of the AS NN (4), and a meteoradar installed on the roof of "Oka" hotel (5).

These facilities permit electric-field observation in both unperturbed atmosphere and the thunderstorm environment. The Boltek EFM-100 fluxmeters were used for recording the quasistatic electric field. For such fluxmeters, the rated discretization frequency of electric signal and sensitivity amounted to $20 \mathrm{~Hz}$ and $\pm 20 \mathrm{~V} / \mathrm{m}^{2}$, respectively. To extend the amplitude range of the received field, the dividers 1:4 were installed for the points at the IAP RAS, the IPM RAS, and the AS NN," and the dividers 1:3 were installed for the point at $\mathrm{SU} N \mathrm{~N}$, which allowed one to record electric fields in the range from -80 to $80 \mathrm{~V} / \mathrm{m}^{2}$.

As a result of processing the measurement results, it was found that since the microcontroller timer of all the employed Boltek EFM-100 fluxmeters operates by about $1.7 \%$ faster, the number of the diurnal readouts was, on the average, by 280435.37 greater than the rated one. The appropriate time normalization was performed during the statistical processing of the averaged data. Synchronization by the GPS signal was performed at the observation point of the IAP RAS. At the remaining observation 
points, the computers, which ensure the data recording and storage, are synchronized via the internet. The data processing involved calculation of the reduction coefficient [25] for each observation point, which is required to allow for the fluxmeter location. It was accomplished for the period of 19 days during which the clouds were totally absent and the wind velocity did not exceed $2 \mathrm{~m} / \mathrm{s}$ according to the meteorological-observation data. It was assumed that the daily-average field in the above-mentioned periods should correspond to the standard value $\mathrm{E}=130 \mathrm{~V} / \mathrm{m}$ of the fair-weather field. The reduction coefficients of the sensors remained almost unchanged during the entire measurement period. The data on the observation points (location, the obtained reduction coefficients, standard deviations, and the asymmetry coefficient) are given in Table 1.

TABLE 1.

\begin{tabular}{|c|c|c|c|c|c|}
\hline $\begin{array}{c}\text { Observation } \\
\text { point }\end{array}$ & Coordinates & $\begin{array}{c}\text { Above- } \\
\text { ground } \\
\text { height, } \mathbf{m}\end{array}$ & $\begin{array}{c}\text { Reduction } \\
\text { coefficient }\end{array}$ & $\begin{array}{c}\text { Standard } \\
\text { deviation, } \\
\text { V/m }\end{array}$ & $\begin{array}{c}\text { Asymmetry } \\
\text { coefficient }\end{array}$ \\
\hline IAP RAS & $\begin{array}{c}56^{\circ} 19^{\prime} 25^{\prime \prime} \mathrm{N} \\
44^{\circ} 01^{\prime} 21^{\prime \prime} \mathrm{E}\end{array}$ & 33 & 3.47 & 139.17 & -3.29 \\
\hline IPM RAS & $\begin{array}{l}56^{\circ} 16^{\prime} 51^{\prime \prime} \mathrm{N} \\
44^{\circ} 04^{\prime} 58^{\prime \prime} \mathrm{E}\end{array}$ & 11 & 2.76 & 145.47 & -1.84 \\
\hline SU NN & $\begin{array}{l}56^{\circ} 17^{\prime} 56^{\prime \prime} \mathrm{N} \\
43^{\circ} 58^{\prime} 48^{\prime \prime} \mathrm{E}\end{array}$ & 17 & 3.55 & 139.17 & -2.74 \\
\hline AS NN & $\begin{array}{l}56^{\circ} 15^{\prime} 40^{\prime \prime} \mathrm{N} \\
43^{\circ} 59^{\prime} 20^{\prime \prime} \mathrm{E}\end{array}$ & 6 & 3.56 & 147.61 & -2.57 \\
\hline
\end{tabular}

The histograms of the ten-minute average values of electric field, which are measured at all four points in the period 2013-2018, are shown in Fig. 2 (compare with the analysis results given in [20]). The mean (median) field values, which were found from these histograms, are equal to $130 \mathrm{~V} / \mathrm{m}$ for all observation points. For further analysis of diurnal variation, as distinct from [20], only the fair-weather events (absence of precipitation including mist and haze, the wind velocity not exceeding $4 \mathrm{~m} / \mathrm{s}$, and the cloud amount not exceeding five oktas) were used. 

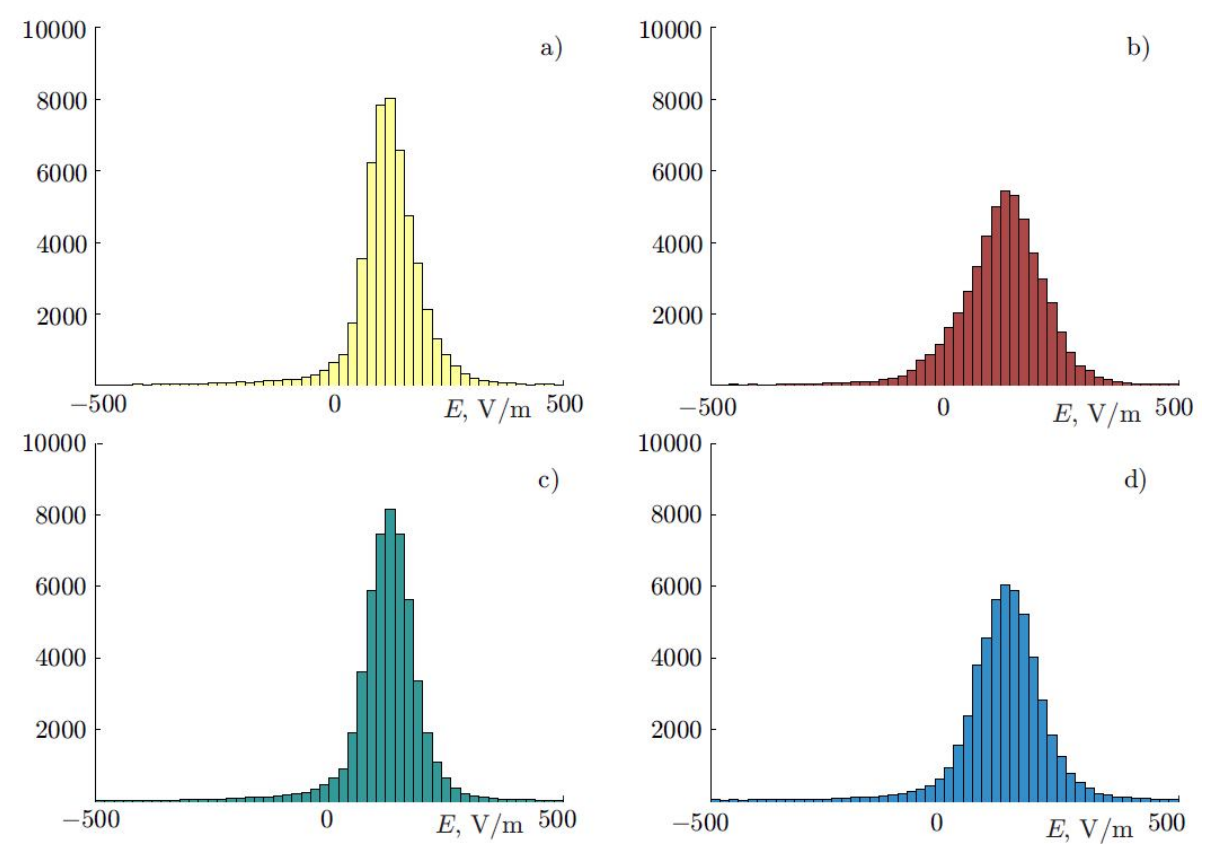

Figure 2. Histograms of the ten-minute averaged values of the electric-field intensity measured in the period 2013-2018, which were developed in the range $\pm 500 \mathrm{~V} / \mathrm{m}$ using the following fluxmeter data: IAP RAS (a), IPM RAS (b), SU NN (c), and AS NN (d).

\section{DIURNAL VARIATION OF THE FAIR-WEATHER ELECTRIC FIELD}

The results of recording the vertical component of the atmospheric electric fair-weather field for 20132018 were analyzed. As a result of processing 139 diurnal records from four observation points, the diurnal (unitary) variation of atmospheric electric field in Nizhny Novgorod was studied with allowance for the season and the day of week. In the above-mentioned record sample, 40 records referred to cold season, 99 records to warm season, 38 records were made in weekend, and 101 records in workdays. The main results of this study are shown in Figs. 3 and 4. Obviously, the diurnal variation, which was observed at all points in Nizhny Novgorod, refers to the "two-maximum variation" type [20]. The evening maximum of diurnal variation coincides by time with the Carnegie-curve maximum, which is a characteristic of the global electric circuit. The maximum values are reached by the field in winter period (which agrees with the observations at continental stations $[5,6,11,22,26,27])$. The field maximum in the first half of the day (09:00-11:00 LT) is characteristic for the urban environment and shows that local effects (primarily, the urban-air contamination by aerosols) significantly contribute to the field perturbation. 


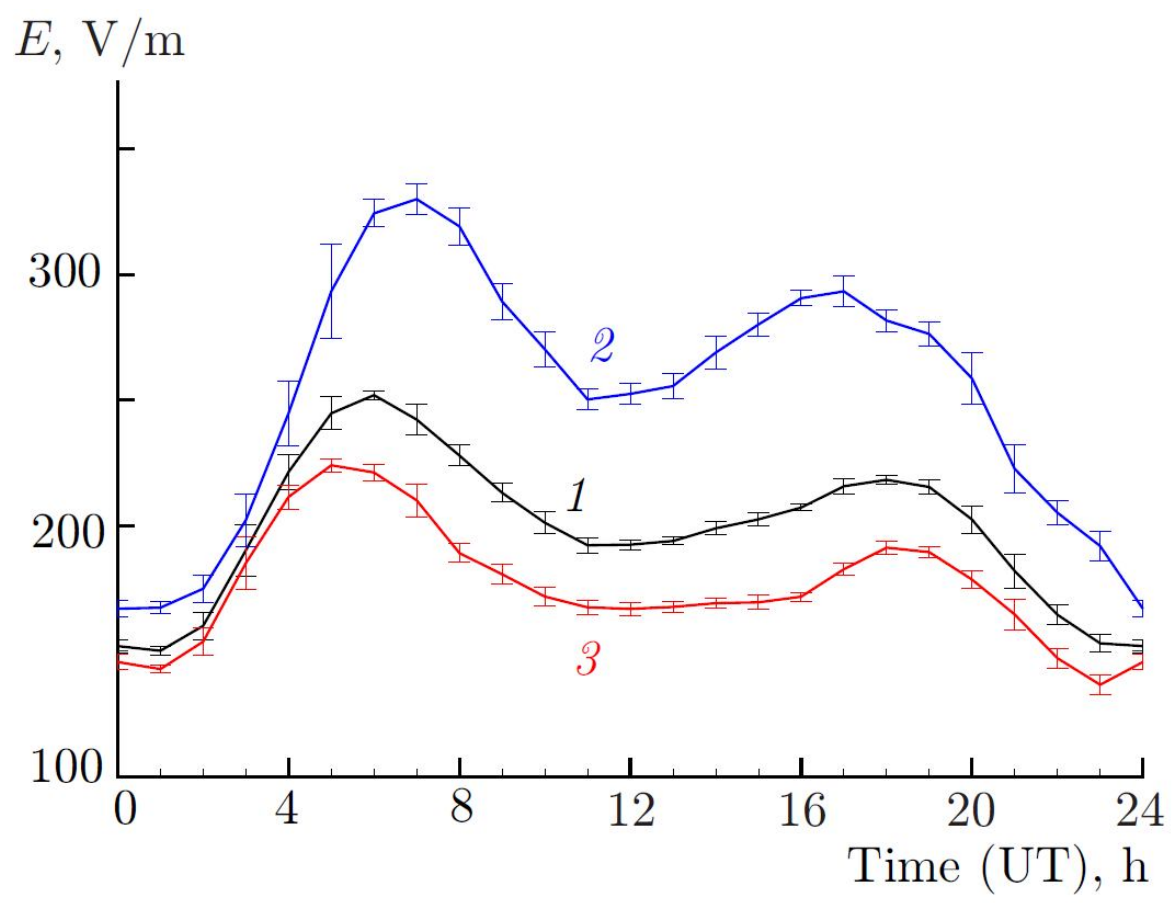

Figure 3. Diurnal variation in the atmospheric electric-field intensity E in Nizhny Novgorod in the period 2013-2018 averaged over all four observation points (hourly averaging): annual average (1), cold period (2), and warm period (3). The vertical lines denote the standard error of the average-value measurement.

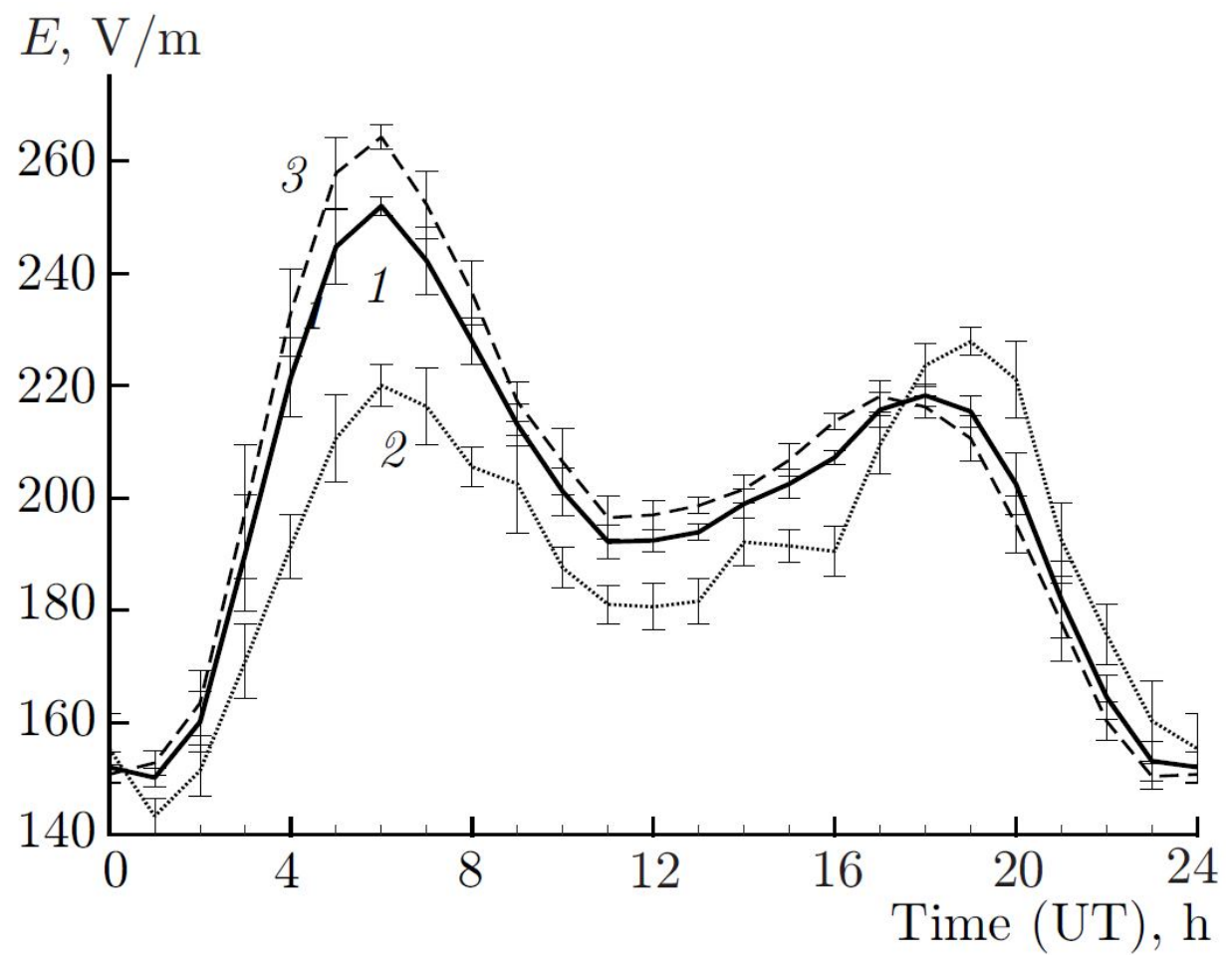

Figure 4. Diurnal variation in the atmospheric electric-field intensity in Nizhny Novgorod in the period 2013-2018 averaged over all four observation points (hourly averaging): annual average (1), weekends (2), and workdays (3). The vertical lines denote the standard error of the average-value measurement. 
Comparison with the results obtained in $[5,6,11,22,26,27]$ shows that the local maximum is observed somewhat later than the sunrise effect is usually observed in the region with low aerosol content and that the morning-maximum amplitude is larger than that of the evening maximum.

Significant difference in the diurnal-variation curves for the cold and warm periods is of interest (see Fig. 3). The cold period is assumed to last from October to April. Figure 3 shows that the global effects prevail over the local ones, especially in weekends in the winter period when the air temperature in the fairweather days is the lowest. In the summer period, contribution from the global effects is comparable with that from the local effects or smaller. The behavior of diurnal variation in the weekends and workdays was studied separately (see Fig. 4). Similar unitary variations have also been observed in other cities [13, $15,20,26,28-30]$.

The obtained results allow one to reveal the role of local effects in the formation of diurnal variation in the mid-latitude regions with temperate continental climate and form the basis for developing a theory that can explain the physical mechanisms of the local-effect influence and develop appropriate parametrizations for finding the near-ground electric field in the weather-climatic models.

\section{SEASONAL VARIATION IN THE ELECTRIC FIELD}

The results of analysis of the monthly-average field values are given in Fig. 5. The 2013-2018 observations in Nizhny Novgorod $\left(56^{\circ} 19^{\prime} 37^{\prime \prime} \mathrm{N}, 44^{\circ} 00^{\prime} 27^{\prime \prime}\right.$ E) show that the maximum values of the field intensity are observed in the cold period from November to March. The field maximum occurs in March. Note that Nizhny Novgorod climate is temperate continental with an average precipitation amount of 653 $\mathrm{mm} / \mathrm{year}$ so that maxima and minima are observed in July and March, respectively. The plotted seasonal variations in the field at three Russia points, which are spaced long distances, with different climatic conditions are also given in the above figure for comparison: a city of Borok of Yaroslavl' province $\left(58^{\circ} 03^{\prime} 45^{\prime \prime} \mathrm{N}, 38^{\circ} 14^{\prime} 23^{\prime \prime} \mathrm{E}\right)$, a city of Yakutsk $\left(62^{\circ} 01^{\prime} 38^{\prime \prime} \mathrm{N}, 129^{\circ} 43^{\prime} 55^{\prime \prime} \mathrm{E}\right)$, and settlement Paratunka (Kamchatka, 52 $57^{\prime} 38^{\prime \prime} \mathrm{N}, 158^{\circ} 14^{\prime} 55^{\prime \prime} \mathrm{E}$ ). The data of the measurements at a point with subtropical climate (a city of Islamabad $33^{\circ} 40^{\prime} \mathrm{N}, 73^{\circ} 10^{\prime} \mathrm{E}$ ) are also given. 


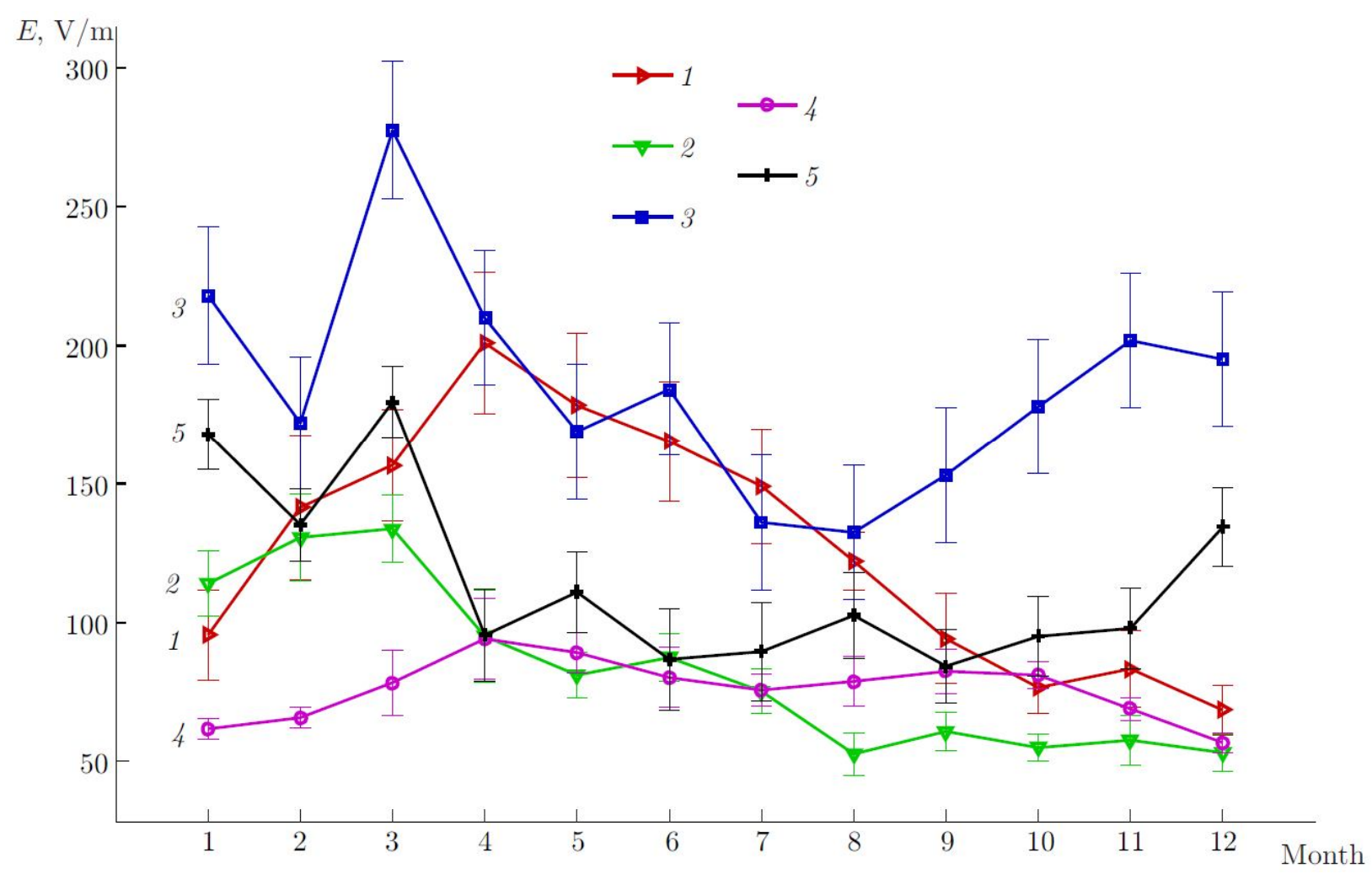

Figure 5. Seasonal variation in the electric-field intensity $E_{\mathrm{z}}$ : the data of "GO Borok" of the Institute of Physics of Earth of the Russian Academy of Sciences IPE RAS in 1998-2009 [22] (1), "GO Paratunka" in 1997-2008 [30] (2), observations in Islamabad in 2013-2015 [14] (3), observations in Yakutsk in 2011 [31] (4), and observations in Nizhny Novgorod 2013-2018 (5). The vertical lines denote the standard error of the average-value measurement.

The longest (14-year) observation period is reflected by the curve of the annual variation of the monthly average field intensity for 1998-2009 at the mid-latitude geophysical observatory in Borok [22]. The observations are performed in an ecologically clean region onshore Rybinsk reservoir. Since Borok and Nizhny Novgorod are located in the Upper-Volga Region at the center of European Plain (the distance between Borok and Nizhny Novgorod is about $405 \mathrm{~km}$ ), the climatic conditions at these points are similar. Therefore, a lower level of anthropogenic load and a longer period of the snow-cover melting are the local features of Borok. The presence of significant April maximum of the average value of the electric-field intensity, which is observed in Borok, is probably related to the above-mentioned features.

The annual maximum of the monthly-average values in Paratunka (Kamchatka) and Nizhny Novgorod is observed in March [31]. The plotted observation period is 1997-2008. The climate in Paratunka is 
transitional from marine to continental. The average July and August temperatures are $13-14{ }^{\circ} \mathrm{C}$, while January temperature amounts to $-9{ }^{\circ} \mathrm{C}$. The average annual precipitation amount is up to $1120 \mathrm{~mm}$. The annual average wind velocity is moderate because the point is surrounded by bald mountains on all sides.

The seasonal variation of the field intensity in Yakutsk [32] has its maxima in the spring and autumn months and minima in the summer and winter months. Continuous observations of intensity of the atmospheric electric field in Yakutsk were started in 2009 and have been performed until present time. The plotted data refer to the period 2009-2013. The field intensity is measured using an electrostatic fluxmeter manufactured by the Research Institute of Radiophysics (Nizhny Novgorod), which is installed on the roof of the main building of the Institute of Cosmophysical Research and Aeronomy of Siberian Branch of the Russian Academy of Sciences. The electric-field observations in Yakutsk are of interest, in particular, because of the strongly continental climate in this city, the average temperatures in which are $-38.6^{\circ} \mathrm{C}$ and $19.5^{\circ} \mathrm{C}$ in January and July, respectively. The annual-average total amount of precipitation is about $238 \mathrm{~mm}$. As a rule, the air in the city is dry especially in summer (the annual-average air humidity is about $68 \%$ ). The observed winter minimum is assumed to be related to a decrease in the field intensity during the winter frost (ice) fogs at the observation point.

The curves of the seasonal field variation in Islamabad [14] have been constructed on the basis of the data for 2015-2017, i.e., a comparatively short period of time. Islamabad is located at the northern border of the Pothohar plateau at a height of $618 \mathrm{~m}$ above sea level. The sensor is installed on the building roof (at a height of about $8 \mathrm{~m}$ from the ground level) at Quaid-i-Azam University $\left(33^{\circ} 45^{\prime} \mathrm{N}, 73^{\circ} 08^{\prime} \mathrm{E}\right)$. This is an one-story building about $7 \mathrm{~m}$ high. The territory is covered by bushy trees and plants. The Islamabad climate is subtropical and under strong influence of seasonal winds, i.e., monsoons, and piedmont location. Islamabad is situated in a moderate humidity region, which is very uncommon for Pakistan since many regions in this country suffer from arid climate. The annual precipitation amount is up to $900 \mathrm{~mm}$ in Islamabad area. June (not July or August) is the warmest month in Islamabad. This is due to monsoons, which come in July-August with abundant precipitation (more than a half of the annual norm) and the average temperature decreases. The average temperature in June is $31.3^{\circ} \mathrm{C}$. January is the coldest month with an average temperature of $10.2^{\circ} \mathrm{C}$. Warm daytime periods and cold nights are typical, occasional 
winter frosts are rather infrequently observed, and sometimes snow falls can take place. Despite the significant amplitude differences (probably, due to a larger height above sea level), the seasonal-variation curve in Islamabad is similar to that observed in Nizhny Novgorod and has its maximum in March. Summing the results of the performed comparative analysis, it can be concluded that in Nizhny Novgorod, as well as at other continental land observation points, the summer maximum due to an increase in the ionospheric potential is masked by the local effects, which lead to an increase in the mean field in the winter months and the spring maximum of the near-ground field.

It should be noted that, e.g., the results of statistical analysis of the material obtained in Borok show that unitary variation (with minimum in the morning hours UT and maximum in the evening hours UT) are often reproduced under the conditions of the unperturbed atmosphere of mid-latitudes of the Northern hemisphere in the winter months (December, January, and February). This conclusion agrees with the results obtained at the mid-latitude Marsta observatory in Sweden $\left(59^{\circ} 56^{\prime} \mathrm{N}, 17^{\circ} 35^{\prime} \mathrm{E}\right)$ and the midlatitude Nagycenk observatory in Hungary $\left(47^{\circ} 38^{\prime} \mathrm{N}, 16^{\circ} 43^{\prime} \mathrm{E}\right)$. Analysis of diurnal variation in the Nizhny Novgorod field in the winter months will be performed in another work in order to reveal global effects.

The theory, which could explain the local features of behavior of the seasonal field variation, has not yet been developed. To develop such a theory, one should reveal the mechanisms of perturbations of the near-ground electric field with allowance for the influence of the meteorological and anthropogenic factors on the dynamics of conductivity of the atmospheric boundary layer.

\section{CONCLUSIONS}

The study results presented in this work have shown that the long-term measurements of the nearground electric field at closely spaced locations yield comprehensive information on the comparative contribution from the global and local effects even under the urban conditions. As a result of processing 139 diurnal records from four observation points spaced $6-8 \mathrm{~km}$, the diurnal variation in the fair-weather atmospheric electric field was studied in Nizhny Novgorod in 2013-2018 for various seasons and days of week. It has 
been shown that the curve of local diurnal variation always has two maxima. The evening maximum of diurnal variation (19:00-20:00 UT) coincides in time with the maximum of the Carnegie curve which characterizes the global electric circuit. The largest amplitude values are reached in the winter season. The field maximum in the first half of the day (09:00-11:00 LT) is characteristic for the urban environment and shows that the local effects, which are related with the presence of aerosol particles in the air, significantly contribute to the diurnal-variation formation, especially in the summer period. Using the measurement data of 2013-2018, we have revealed the seasonal variation of the monthly-average values of the fair-weather atmospheric electric field (with the maximum values in the winter and spring periods) and compared it with the results of the seasonal-variation measurements in other regions of the world. It should be noted that possible effects of geomagnetic and solar activities, which are the most pronounced in high latitudes and influence the diurnal and seasonal variations of electric field, remain beyond the scope of this study (for more detailed information on this issue see [31, 33, 34]).

The obtained results are useful for revealing the role of global and local effects in formation of diurnal variation in the mid-latitude regions with temperate continental climate. They can serve as the basis for developing a theory that can explain physical mechanisms of these effects and construct rather simple parametrizations for obtaining the near-ground electric field in the weather-climatic models.

We thank Yu.V. Shlyugaev for assistance in performing the experiments. The study was financially supported by the Russian Foundation for Basic Research and the Project for International Exchange of London Royal Society (IEC R2 170075) between Russia and Great Britain (project No. 17-55-10014 KO-a). K.A.Nicoll is thankful for financial support of the NERC via Independent Research Fellowship (NE/L011514/1 and NE/L011514/2).

\section{REFERENCES}

1. S. J.Mauchly, Phys. Rev., 18, 161 (1921).

2. S. J.Mauchly, J. Geophys. Res., 28, No. 3, 61 (1923).

3. F. J. W.Whipple, Quart. J. Royal Meteor. Soc., 55, No. 232, 351 (1929). 
4. R. Markson, Bull. Amer. Meteor. Soc., 88, No. 2, 223 (2007).

5. N. A. Paramonov, Dokl. Akad. Nauk SSSR, 70, No. 1, 37 (1950).

6. A.Okawati, J. Geom. Geoel., 12, No. 3, 129 (1961).

7. J.Tacza, J.-P.Raulin, E.Macotela, et al., J. Atmos. Sol.-Terr. Phys., 120, 70 (2014).

8. M.Kubicki, A.Odzimek, and M.Neska, Atmos. Res., 178-179, 329 (2016).

9. W. S.Whitlock and J.A.Chalmers, Quart. J. Royal Meteor. Soc., 82, No. 353, 325 (1956).

10. R. G. Harrison, Surv. Geoph., 34, No. 2, 209 (2013).

11. M. Kubicki, S.Michnowski, and B.MysLek-Laurikainen, Proc. 13th Int. Conf. Atmosph. Elect. August 13-17, 2007. Beijing, China, p 50.

12. M. Golkowski, M.Kubicki, M.Cohen, et al., Acta Geoph., 59, No. 1, 183 (2011).

13. A. J. Bennett and R.G.Harrison, Weather, 62, No. 10, 277 (2007).

14. S.F.Gurmani, N.Ahmad, J.Tacza, and T. Iqbal, J. Atmos. Sol.-Terr. Phys., 179, 441 (2018).

15. I.M. Imyanitov and E.V. Chubarina, Trudy Glavnoi Geofiz. Obs., No. 110, 7 (1960).

16. J. A.Chalmers, Atmospheric Electricity [in Russian], Gidrometeoizdat, Leningrad (1974).

17. S. Israelsson, E.Knudsen, and S.V.Anisimov, J. Atmos. Terr. Phys., 56, No. 12, 1545 (1994).

18. S. V. Anisimov, E.A.Mareev, N.M. Shikhova, et al., Nonlin. Proc. Geophys., 20, No. 5, 819 (2013).

19. R. G. Harrison and K. A. Nicoll, J. Atmos. Sol.-Terr. Phys., 179, 239 (2018).

20. K. A. Nicoll, R. G. Harrison, V. Barta, et al., J. Atmos. Sol.-Terr. Phys., 184, 18 (2019).

21. J.C. Matthews, M. D.Wright, D.Clarke, et al., J. Electrost., 97, 42 (2019).

22. S. V. Anisimov, N.M. Shikhova, and K.V.Afinogenov, Radiophys. Quantum Electron., 56, Nos. 1112,709 (2013).

23. E. J. Adlerman and E.R.Williams, J. Geophys. Res. Atmos., 101, No. D23, 29679 (1996).

24. E. A. Mareev and E.M.Volodin, Geophys. Res. Lett., 41, No. 24, 9009 (2014).

25. T. V.Kudrinskaya, K. A. Boldyreva, O. V. Novikova, et al., Nauchn. Mysl Kavk., No. 4, 95 (2012).

26. H. G. Silva, R.Conceicao, M. Melgao, et al., Env. Res. Lett., 9, No. 11, 114025 (2014).

27. B. Xu, D. Zou, B.Y.Chen, et al., J. Atm. Solar-Terr. Phys., 97, 85 (2013).

28. N. Ahmad, S. F. Gurmani, R. M.Qureshi, and T. Iqbal, Adv. Space Res., 63, No. 2, 927 (2019).

29. H. G. Silva, R.Conceicao, M. A. H.Khan, et al., J. Electrost., 84, 32 (2016).

30. V.M. Sheftel, A.K.Chernyshev, and S.P.Chernysheva, J. Geophys. Res., 99, No. D5, 10793 (1994). 
31. S. E. Smirnov, S. V. Anisimov, and N. M. Shikhova, in: Proc. Vth Int. Conf. "Solar-Earth Relations and Physics of Earthquake Precursors.” August 2-7, 2010. Paratunka, Kamchatka Region, p. 208.

32. A. A.Toropov, V. I. Kozlov, and R. R. Karimov, Nauka Obraz., No. 2, 58 (2016).

33. A. G. Apsen, Kh.D.Kanonidi, S.P.Chernyshova, et al., Magnetospheric Effects in Atmospheric Electricity [in Russian], Nauka, Moscow (1988).

34. E. Williams and E.Mareev, Atmos. Res., 135-136, 208 (2014). 